\title{
Update on Direct Oral AntiCoagulants (DOACs)
}

\section{Perioperative "switching", drug interactions and persistence}

\author{
J. Koscielny'; C. Rosenthal2; C. von Heymann ${ }^{3}$ \\ ${ }^{1}$ Gerinnungsambulanz mit Hämophiliezentrum im ambulanten Gesundheitszentrum (AGZ), Charité Campus Mitte \\ (CCM), Universitätsmedizin Berlin; ${ }^{2}$ Klinik für Anästhesiologie mit Schwerpunkt operative Intensivmedizin, Charité \\ Campus Virchow Klinikum (CVK), Universitätsmedizin Berlin; ${ }^{3}$ Klinik für Anästhesie, Intensivmedizin, Notfallmedizin \\ und Schmerztherapie, Vivantes Klinikum im Friedrichshain, Berlin
}

\section{Keywords}

DOACs, rivaroxaban, apixaban, edoxaban, dabigatran, "switching", drug interactions, persistence

\section{Summary}

Recent findings require an update of previous recommendations for the perioperative use of Direct Oral AntiCoagulants (DOACs). A break in preoperative treatment of 24-96 hours is recommended based on the pharmacokinetic profiles of DOACs and depends on individual patient characteristics, their renal and possibly liver function, and their surgery-related risk of bleeding. In cases of renal or hepatic insufficiency, whether to extend the preoperative interruption of Ila- and Xa-inhibitors is a clinical decision that must be reached on an individual patient basis. In cases of epidural or spinal anaesthesia, more conservative pausing-intervals are recommended due to the risk of persistent neurologic deficits (e.g., paraplegia) following the development of spinal subdural and epidural haematomas. Elective surgery should be postponed according to these recommendations. Preoperative "bridging" with LMWH (more precisely referred to as "switching") should be omitted

Korrespondenzadresse

Priv.-Doz. Dr. med. Jürgen Koscielny

Gerinnungsambulanz mit Hämophiliezentrum

im ambulanten Gesundheitszentrum (AGZ)

Charité, Universitätsmedizin Berlin,

Campus Charité Mitte

Charitéplatz 1, Durchgang Luisenstr. 13, D-10117 Berlin (Germany)

Tel. + 4930 - 450525181, Fax. +49 $30-450525913$

E-mail: juergen.koscielny@charite.de due to a significantly increased risk of bleeding. In addition, the incidence of perioperative thromboembolic risks, such as DVT, PE, and stroke, are no different whether interruption or "switching" is undertaken. Postoperatively, the DOACs can be reinstituted within the first 24 hours. In cases of major surgery or if there is a higher risk of bleeding, resumption of DOACS should only begin after 24-72 hours. In patients with an elevated thromboembolic risk, transient postoperative LMWH administration can be recommended during this period.

Interaction of DOACs with other drugs usually occurs during the absorption, transport and elimination of these drugs. Therefore, substance-specific restrictions and recommendations should be observed during these times. In everyday clinical practice, webbased, independent information portals on drug-interactions are very helpful in providing safe and rapid information about potential interactions when DOACs are used in combination with other drugs, especially during perioperative management.

Non-adherence to medications is a worldwide problem that has dangerous and costly consequences. Present data suggest that persistence is the primary factor that supports adherence.

Update Direkte Orale AntiKoagulanzien (DOAKs) Perioperatives "Switching", Medikamenteninteraktionen und Persistenz

Phlebologie 2018; 47: 137-145

Nachdruck aus und zu zitieren als: Hämostaseologie 2017; 37: 267-275 https://doi.org/10.5482/HAM0-16-10-0041 received: October 8, 2016

accepted in revised form: August 22, 2017 epub ahead of print: September 27, 2017
Despite the adherence data presented in the DOACS approval studies (e.g., persistence in the treatment of acute venous thromboembolism has been reported to be between 94-99\%), the first registries and meta-analyses provide sobering results regarding the incidence of persistence and the success rate of interventions designed to improve adherence with DOACs in cases of long-term usage.

\section{Schlüsselwörter}

DOAKs, Rivaroxaban, Apixaban, Edoxaban, Dabigatran, „Switching”, Medikamenteninteraktionen, Persistenz

\section{Zusammenfassung}

Aktuelle Erkenntnisse erfordern die Aktualisierung früherer Empfehlungen zum perioperativen Einsatz von direkte orale Antikoagulanzien (DOAKs). Auf Grundlage der pharmakokinetischen Profile wird in Abhängigkeit von Nierenfunktion, ggf. Leberfunktion sowie individuellem und eingriffsspezifischem Blutungsrisiko eine präoperative Pausierung von 24-96 Stunden in Abhängigkeit von dem verwendeten DOAK empfohlen. Bei schwerer Nieren- oder Leberinsuffizienz ist es eine individuelle, klinische Entscheidung, die präoperative Pause für die Xa-Inhibitoren zu verlängern. Für Patienten mit rückenmarksnahen Regionalanästhesieverfahren gelten aufgrund des Risikos von spinal sub- und epiduralen Hämatomen und dem Risiko bleibender schwerer neurologischer Defizite (Querschnittslähmung) sehr konservative Intervalle im oberen Pausierungsbereich. Ein bereits präoperativ beginnendes „Bridging” mit 
NMH (eigentlich "Switching") sollte wegen signifikant erhöhter Blutungsrisiken unterbleiben. Das perioperative Thromboembolierisiko (z.B. Thrombose, Lungenembolie, Hirninfarkt) ist nach einer präoperativen Pause bzw. einem präoperativen "Switching" nicht unterschiedlich. Postoperativ können DOAKs innerhalb von $24 \mathrm{~h}$, nach größeren Eingriffen bzw. höherem Blutungsrisiko erst nach 24-72 Stunden wiederaufgenommen werden. Eine postoperative, passagere Umstellung auf eine NMH-Gabe ("Switching") bei erhöhtem venösem Thromboembolierisiko kann in diesem Zeitraum erfolgen.

Medikamenteninteraktionen von direkten oralen Antikoagulanzien treten meist bei der Absorption, beim Transport und bei der Elimination von anderen Medikamenten auf. Hierbei sind substanzspezifische Einschränkungen und Empfehlungen zu beachten. Um im klinischen Alltag eine sichere und schnelle Information, auch über DOAKs in Kombination mit anderen Medikamenten im perioperativen Management, zu erhalten, sind webbasierte, unabhängige Informationsportale sehr hilfreich.

Die Non-Adhärenz von Medikamenten ist weltweit verbreitet, ist gefährlich und teuer in ihren Folgen. Die aktuellen Daten beschreiben vorwiegend die Persistenz als ein orientierendes Maß für die Adhärenz. Unabhängig von den Zulassungsstudien der DOAKs (Persistenz bei der Therapie akuter venöser Thromboembolien zwischen 94 - 99\%) liefern erste Register und Metaanalysen ernüchternde Ergebnisse zur Persistenz und zur Verbesserung der Adhärenz der DOAKs in der Langzeitanwendung.

\section{Introduction}

The major medical indications for anticoagulant therapy are prophylaxis for stroke and thromboembolism associated with atrial fibrillation and for the treatment and prophylaxis of venous thromboembolism and pulmonary embolism. Currently, the established vitamin $\mathrm{K}$ antagonists are increasingly being replaced by or supplemented with Direct Oral AntiCoagulants (DOACs) - namely, the thrombin-inhibitor dabigatran and the Xa-inhibitors rivaroxaban, apixaban and edoxaban.
Dabigatran received EU drug approval in September 2011, rivaroxaban in December 2011, apixaban in January 2013, and edoxaban in August 2015 (1-10).

The number of patients taking DOACs has increased in conjunction with the number of surgical procedures in those same patients. For instance, a prespecified analysis of the RE-LY trial showed that approximately $25 \%$ of the study participants taking dabigatran underwent an invasive elective or emergency procedure within 24 months after the start of treatment (1).

Thus, an important question that often arises in the perioperative period is when and how long before a procedure should DOACs be discontinued? Appropriate guidelines are particularly needed because antidotes are not available for all DOACs. To address this gap in knowledge, different recommendations and/or guidelines for perioperative management of DOACs have been put forth (11-22). These recommendations are not primarily based on data from prospective (randomized) clinical trials, but rather they have been formulated based on pharmacokinetic considerations and registry data derived from clinical practice (23-28). Recent results from these registries show that preoperative „switching" (e.g., to LMWH) procedures are associated with higher bleeding rates.

Furthermore, approximately seven percent of the undesired effects associated with DOACS are due to drug interactions, with the incidence increasing along with the number of concomitant drugs $(29,30)$.

Nonadherence to medications is a worldwide problem that has dangerous and expensive consequences. According to a WHO report only $50 \%$ of patients on average with chronic diseases are adherent to their medications in developed countries (31). The cost of nonadherence to the US health care system is estimated to be approximately 300 billion dollars per year. This represents approximately $13 \%$ of the total cost of the US health care system (32). The main cost drivers are avoidable hospitalizations that cost approximately 100 billion dollars. In Germany, these costs are estimated at 7.5 - 10 billion euros per year (33). Despite the adherence data in the DOAC approval studies (e.g., adherence to the treatment of acute venous thromboem- bolism was reported to be between 94-99\%), the first registries and meta-analyses provide sobering results about the level of adherence. Consequently, interventions aimed at improving adherence to DOACs in cases of long-term usage are urgently needed.

The purpose of this review is to provide a comprehensive review on the perioperative management of DOACs, the impact of drug interactions on DOAC plasma levels and the challenge of patient adherence, factors that merit close attention so that medical care for patients using DOACs can be improved in the long run.

\section{Perioperative management of DOACs}

The European Heart Rhythm Association (EHRA) has published recommendations for the periinterventional and perioperative management of DOACs (11). These recommendations also take into account the presence of renal insufficiency and are summarized, along with other recommendations, via an "APP“ BridgeAnAcoag (App-Store and Googleplay-Store) from the ACC (American College of Cardiology), as follows: in general, the partial elimination by the kidneys requires timely discontinuation of DOACs in the perioperative or periinterventional phase, especially in patients with renal insufficiency. In patients with normal renal function, a preoperative discontinuation of DOACs for 24 hours (2-2.5 half-lives) should be sufficient to reduce plasma-levels to at least $25 \%$, which should be safe for surgical procedures with a low risk of bleeding $(17,43)$.

Only the thrombin inhibitor dabigatran, with a mean half-life of 13.4 hours with a normal glomerular filtration rate (GFR) of $>80 \mathrm{ml} / \mathrm{min}$, should be discontinued $36-48$ hours before surgery when there is doubt about the timing of the last dose or concerns about an increased risk of bleeding. In a study by Healey et al. (1) that investigated the periinterventional discontinuation of dabigatran as a subgroup analysis of the RE-LY study, this time interval was associated with a significantly lower rates of bleeding complications compared with the interruption of warfarin. 
The recommended 24-hour interruption interval comprises roughly 2 halflives of DOACs, which is comparable to the standard practice of preoperative management of LMWH (17).

The presence of renal insufficiency requires a longer period of discontinuation for all DOACs, as at least $25 \%$ of all substances are eliminated renally. Thus, depending on the severity of renal insufficiency, treatment discontinuation of $\geq 48$ hours (approximately 4-5 half-lives) is recommended for the group of factor Xa-inhibitors ( Table 1 ).

For dabigatran, which is predominantly (80\%) eliminated through the kidneys, discontinuation for $72-96$ hours is recommended depending on the creatinine clearance ( Table 2) $(11,17,44)$. Because of the diagnostic imprecision of serum creatinine levels in cases of renal insufficiency, renal function in patients with suspected renal impairment should preferably be monitored with a measured or calculated creatinine clearance.

In addition, and as an exception, it may be useful to measure DOAC plasma levels preoperatively using the "diluted thrombin time“ (DTT) or a chromogenic assay for dabigatran or a calibrated anti-Xa activity for the FXa-inhibitors (apixaban, edoxaban, rivaroxaban). Even though the plasma levels do not correlate strictly with the risk of bleeding, they may be useful for assessing the risk when a surgical procedure with an increased bleeding risk is undertaken. Despite a lack of evidence from prospective trials, some centres have determined that a cut-off plasma level for DOACs of $<30 \mathrm{ng} / \mathrm{ml}$ is safe with respect to perioperative bleeding-risk.

Placement and removal of epidural catheters as well as administering spinal anaesthesia also require preinterventional pausing of DOACs. The recommended pausing intervals for neuraxial analgesia/ anaesthesia have been developed under the auspices of the German Society of Anaesthesiology and Intensive Care Medicine (17) ( Table 3). These pausing intervals correlate largely with the abovementioned recommendations $(17,44)$, though they reside in the more conservative upper limit of pausing-intervals due to the high risk and serious consequences of periprocedur-
Tab. 1 Time of last DOAC intake (apixaban, edoxaban, rivaroxaban) before elective surgery

\begin{tabular}{lll}
\hline $\begin{array}{l}\text { Creatinine } \\
\text { clearance } \\
\text { (ml/min) }\end{array}$ & \multicolumn{2}{l}{ Bleeding risk } \\
\cline { 2 - 3 } & low & high \\
\hline$\geq 80$ & $\geq 24 \mathrm{~h}$ & $\geq 48 \mathrm{~h}$ \\
\hline $50-80$ & $\geq 24 \mathrm{~h}$ & $\geq 48 \mathrm{~h}$ \\
\hline $30-50$ & $\geq 24 \mathrm{~h}$ & $\geq 48 \mathrm{~h}$ \\
\hline $15-30$ & $\geq 36 \mathrm{~h}$ & $\geq 48 \mathrm{~h}$ \\
\hline$<15$ & no approval & $\begin{array}{l}\text { contraindi- } \\
\text { cated } \\
\text { no approval }\end{array}$ \\
\hline
\end{tabular}

al bleeding. In this scenario, the measurement of DOAC plasma levels may be helpful if doubt exists about the last time oral anticoagulants were ingested. In our view, in cases of uncertainty about this timing, one should refrain from neuraxial anaesthesia/analgesia to minimize the risk of severe neurological complications resulting from the development of a spinal subdural or epidural haematoma.

\section{No preoperative "switching" of DOACs}

The widely used (12-14) practice of "bridging" with LMWH for patients taking vitamin $\mathrm{K}$ antagonists (VKA) is strongly discouraged during the preoperative DOAC break $(11,18-22,45,46)$, since this may be associated with a higher risk of periprocedural bleeding.

In practice, the different meanings of "bridging" and "switching" should be considered and used correctly.

Tab. 2 Time of last DOAC intake (dabigatran) before elective surgery

\begin{tabular}{l|l|l}
\hline $\begin{array}{l}\text { Creatinine } \\
\text { clearance } \\
(\mathrm{ml} / \mathrm{min})\end{array}$ & \multicolumn{2}{l}{ Bleeding risk } \\
\cline { 2 - 3 } & low & high \\
\hline$\geq 80$ & $\geq 24 \mathrm{~h}$ & $\geq 48 \mathrm{~h}$ \\
\hline $50-80$ & $\geq 24-48 \mathrm{~h}$ & $\geq 48-72 \mathrm{~h}$ \\
\hline $30-50$ & $\geq 48-72 \mathrm{~h}$ & $\geq 96 \mathrm{~h}$ \\
\hline $15-30$ & no approval & no approval \\
\hline$<15$ & no approval & no approval \\
\hline
\end{tabular}

- "bridging": Preoperative overlapping of an oral anticoagulation with VKA (long half-life) with parenteral LMWH or UFH until the overlapping resumption of oral anticoagulation postoperatively.

- "switching": Usually, exchange from one anticoagulation regime with a short half-life (such as s.c. LMWH) to another anticoagulant with a short half-life (for example, DOAC) without overlap of anticoagulant effects of both medications.

Because the preoperative pausing intervals for DOACs are usually quite short due to their short half-lives and because there is no evidence for more effective avoidance of thromboembolic complications associated with preoperative switching, DOACs should be stopped preoperatively according to recommended time-intervals ( $>$ Table 1 and $>$ Table 2 ) before surgery/ interventions. Based on recent data analysis, the "switching" method from the registration studies of individual DOACs showed no reduction in the rate of thromboembolic complications, although there was a significantly increased risk of periinterventional bleeding ( $>$ Table 4 ).

In the subgroup analysis by Douketis et al. (47), the rate of perioperative/periinterventional major bleeding events in patients receiving dabigatran was $6.5 \%$ with "switching" versus $1.8 \%$ without "switching" ( $p<0.001)$. In contrast, the rates of thromboembolic events and serious embolic complications did not differ between the "switching" and "no switching" groups: $1.2 \%$ vs. $0.6 \%,(\mathrm{p}=0.16)$ and $0.5 \%$ vs. $0.3 \%$ $(\mathrm{p}=0.46)$, respectively. These results provide evidence that peri-interventional therapy with dabigatran for atrial fibrillation does not require "switching" with heparin prior to minor procedures with a low risk of bleeding. "Real-life" data from a registry in Saxony that investigated the peri-interventional/perioperative bleeding rate in DOAC-treated patients also supports that preinterventional "switching" is not required $(23,24,48)$. The majority of the patients examined were taking rivaroxaban. Of a total of 863 interventions and minor surgical procedures, there were 3 major bleeding events in the group of patients without "switching" to heparin ver- 
Tab. 3 The recommended time intervals for the individual substances before or after neuroaxial anesthesia / analgesia - from the German Society of Anaesthesiology and Intensive Care Medicine (DGAI) guidelines (17)

\begin{tabular}{|l|l|l|l|}
\hline Drug & $\begin{array}{l}\text { Half-time in } \\
\text { plasma }\end{array}$ & $\begin{array}{l}\text { Before } \\
\text { neuroaxial process }\end{array}$ & $\begin{array}{l}\text { After } \\
\text { neuroaxial process }\end{array}$ \\
\hline $\begin{array}{l}\text { dabigatran } \\
\text { (max. } 1 \times 150-220 \mathrm{mg} / \mathrm{d})\end{array}$ & $14-17 \mathrm{~h}^{2}$ & $28-34 \mathrm{~h}$ & $6 \mathrm{~h}$ \\
\hline $\begin{array}{l}\text { dabigatran } \\
(\mathrm{max} .2 \times 150 \mathrm{mg} / \mathrm{d})^{4}\end{array}$ & $14-17 \mathrm{~h}^{2}$ & $56-85 \mathrm{~h}$ & $6 \mathrm{~h}$ \\
\hline $\begin{array}{l}\text { rivaroxaban } \\
(1 \times 10 \mathrm{mg} / \mathrm{d})\end{array}$ & $11-13 \mathrm{~h}^{2,3}$ & $22-26 \mathrm{~h}$ & $4-5.5 \mathrm{~h}$ \\
\hline $\begin{array}{l}\text { rivaroxaban } \\
(2 \times 15 \mathrm{mg} / \mathrm{d}, 1 \times 20 \mathrm{mg} / \mathrm{d})^{4}\end{array}$ & $11-13 \mathrm{~h}^{2,3}$ & $44-65 \mathrm{~h}$ & $4-5.5 \mathrm{~h}$ \\
\hline $\begin{array}{l}\text { apixaban } \\
(2 \times 2.5 \mathrm{mg} / \mathrm{d})\end{array}$ & $10-15 \mathrm{~h}^{2,3}$ & $26-30 \mathrm{~h}$ & $5-7 \mathrm{~h}$ \\
\hline $\begin{array}{l}\text { apixaban } \\
(2 \times 5 \mathrm{mg} / \mathrm{d})^{4}\end{array}$ & $10-15 \mathrm{~h}^{2,3}$ & $40-75 \mathrm{~h}$ & $5-7 \mathrm{~h}$ \\
\hline $\begin{array}{l}\text { edoxaban } \\
(1 \times 30 \mathrm{mg} / \mathrm{d})\end{array}$ & $10-14 \mathrm{~h}^{2,3}$ & $20-28 \mathrm{~h}$ & $6-7 \mathrm{~h}$ \\
\hline $\begin{array}{l}\text { edoxaban } \\
(1 \times 60 \mathrm{mg} / \mathrm{d})^{4}\end{array}$ & $10-14 \mathrm{~h}^{2,3}$ & $40-60 \mathrm{~h}$ & $6-7 \mathrm{~h}$ \\
\hline
\end{tabular}

${ }^{1}$ under ASA-medication (100 mg): free intervalls of additional anticoagulants $4-5$ half-times in plasma) before neuroaxial process

${ }^{2}$ CAVE: half-time in plasma depending on renal function

${ }^{3}$ CAVE: half-time in plasma depending on liver function

${ }^{4}$ individual risk calculation

sus 7 major bleeding events with "switching" $(0.5 \%$ vs. $2.7 \%, p=0.010)$. In a prospective cohort study of dabigatran with a high medication adherence of $77 \%$, the perioperative bleeding rate without switching was $1.8 \%$ (95\% confidence interval: $0.7-3.0,10$ of 541 patients) (27). The only thromboembolic event was a transient ischaemic attack (TIA) $(0.2 \%$; $95 \%$ - confidence interval: $0-0.5$ ). The last dose of dabigatran was given $24 \mathrm{~h}, 48 \mathrm{~h}$ or $96 \mathrm{~h}$ (46\%, $37 \%$ and $6 \%$ ), preoperatively. A first postoperative dose of dabigatran of $75 \mathrm{mg}$ was administered to $40 \%$ of patients at the day of procedure. Another prospective cohort study in patients taking dabigatran, who underwent elective surgery with a standardized break protocol and who were monitored using laboratory analysis, showed the same low perioperative bleeding and low TIA rates of $0.6 \%$ (28). Data from the ORBIT-AF registry (25) re-confirmed the significantly increased incidence of bleeding and other complications after "switching" in a group of patients taking dabigatran: $7 \%$ of the overall group re- possible to generalize these findings to the management of other more involved surgical procedures. Interestingly, in a risk-adjusted comparison of groups, thromboembolic complications (stroke, systemic embolism, myocardial infarction) occurred significantly more often without interruption of anticoagulation in the warfarin group (43). This investigation supports the conclusion that for minor surgical procedures and diagnostic interventions, continued anticoagulation with apixaban (interruption less than $24 \mathrm{~h}$ ) is not associated with more bleeding events compared to a longer interruption of anticoagulation. Periprocedural registry data is not yet available for edoxaban.

\section{Postoperative management of DOACs}

The postoperative resumption of anticoagulation with DOACs in the cited studies was usually started in the evening of the day of surgery or on the $1^{\text {st }}$ to $2^{\text {nd }}$ postoperative day. This approach can be recommended safely for the majority of operations, especially those with a low bleeding risk. For operations with an increased risk of bleeding, patients with indwelling epidural catheters for postoperative analgesia or patients with renal or hepatic failure, a later resumption of DOACs seems to be advisable (49). Particularly when using epidural catheters that often remain in place for 3-5 days postoperatively, DOAC treatment should be resumed only after removal of the epidural catheter. Because of this long recommended pausing interval for DOACs prior to catheter removal, patients face an increased risk of thromboembolism.

In these cases, postoperative temporary "switching" to LMWH or UF-heparin for anticoagulation is a favourable solution.

When comparing the recommendations for the perioperative management of anticoagulation for patients receiving VKA or DOACs, it appears that "bridging" of VKA is indicated in certain circumstances. This should be considered at least for the period prior to surgery or the intervention in patients with an increased thromboembolic risk. "Switching" is probably not required in most patients with DOACs, due to the 
short interruption intervals. A reason for bridging of VKA is the very long half-life of phenprocoumon versus warfarin.

Of note, these recommendations are being made in the absence of data from the "real-life" application of DOACs focusing on major surgery and interventions with an increased bleeding risk. In the future, it is possible that major differences in the perioperative management of VKA and DOACs will no longer exist, and the preoperative management of patients on DOACs will also be simplified.

During the postoperative phase, a shortterm "switching" to LMWH or UFH, a long-standing protocol that is practiced with VKA, may be indicated, especially in high-risk situations such as acute perioperative deterioration of renal function, liver function, perioperative bleeding, large wound surface, etc. (16). For the majority of interventions, the resumption of DOACs on the first or second day will make postoperative anticoagulation more simple and standardized.

\section{Postponement of operations and DOACs}

Current guidelines give no additional recommendations for preoperative anticoagulation management when a surgical procedure for patients taking DOACs is postponed for more than 24-48 hours because of organizational, medical or other reasons. In such situations, the above-mentioned recommendations are invalid $(11,17)$. Every effort should be made to schedule the day of surgery so that the anticoagulation management can be managed properly and factors, such as the individual risk of bleeding, thromboembolism and stroke at the time of surgery, can be properly addressed. If there are concerns about possible thromboembolic risks associated with the prolonged pausing of therapeutic anticoagulation, bridging with LMWH may be performed.

\section{Drug interactions of DOACs}

Most patients are usually taking several drugs simultaneously, resulting in drug-
Tab. 4

Perioperative "major bleedings" under DOACs $(24,25,27,28$, 47) with or without switching to LMWH (low molecular weight heparin)

\begin{tabular}{|l|l|l|l}
\hline Drug & $\begin{array}{l}\text { With "switching" } \\
\text { to LMWH } \\
(\%)\end{array}$ & $\begin{array}{l}\text { Without "swich- } \\
\text { ting" to LMWH } \\
(\%)\end{array}$ & $\begin{array}{l}\text { Signifi- } \\
\text { cance }\end{array}$ \\
\hline dabigatran (47) & 6.5 & 1.8 & $\mathrm{p}<0.001$ \\
\hline $\begin{array}{l}\text { rivaroxaban (24) } \\
\text { (apixaban) }\end{array}$ & 2.7 & 0.5 & $\mathrm{P}=0.010$ \\
\hline dabigatran (27) & - & 1.8 & \\
\hline dabigatran (28) & - & 0.6 & $\mathrm{p}<0.0001$ \\
\hline dabigatran (25) & 5.0 & 1.3 & \\
\hline
\end{tabular}

drug interactions. The definition of a drug interaction is one that results in a negative impact on the therapeutic use (synergistic or antagonistic drug effects). These interactions may occur during absorption, transportation, elimination and distribution of the drugs. For DOACs, the first three routes are of great importance (50-56). To varying degrees, DOACs are substrates of CYP3A4 and/or the P-glycoprotein-transporter, which are also inhibitors of transport processes in various cell types. Usually, a co-medication will influence these proteins, placing the DOACs in a "victim" role and unveiling a new dimension of possible interactions (50-56). Approximately seven percent of unwanted drug effects are due to drug interactions, and the incidence increases exponentially with the number of co-administered medications (29-30). To receive fast and reliable information in clinical practice, the following web-based, independent providers are helpful: www.dosing.de or

www.wechselwirkungscheck.de

From a pharmacological view, the exposure of the co-administered drug at steady state is crucial. Here, the degree of accumulation of the "victim" drug, i.e., how much higher the concentration at steady state is compared with the first dose, will be determined (50-56). - Figure 1 provides an overview for orientation.

\section{Dabigatran}

Dabigatran has a low potential for drug interactions $(19,53,54)$. It is neither metabolized through CYP-450 enzymes nor does it affect them. However, it is a substrate of the efflux transporter P-glycoprotein, resulting in increased dabigatran plas- ma concentrations when P-glycoprotein inhibitors are used simultaneously. Therefore, concomitant use of dabigatran with P-glycoprotein inhibitors such as amiodarone, verapamil, ketoconazole, cyclosporine, itraconazole and dronedarone is contraindicated due to an increased risk of bleeding. Dabigatran administration combined with other anticoagulants, antiplatelet drugs, NSAIDs (nonsteroidal antiinflammatory drugs), SSRIs (selective serotonin reuptake inhibitors), SSNRI (selective serotonin-norepinephrine-reuptake-inhibitor) and other drugs that may affect haemostasis is also contraindicated (54). Exceptions include when there is a change of the anticoagulant therapy or when unfractionated heparin is given in doses that are necessary to prevent clot formation within central venous or arterial lines (19, $53,54)$. When dabigatran and the aforementioned drugs have to be administered concomitantly, it is recommended to adjust the dose of dabigatran, for example, from 2 $\mathrm{x} 150 \mathrm{mg}$ to 2 x $110 \mathrm{mg}$ daily.

Concomitant use of dabigatran with non-retarded P-glycoprotein-inductors, such as carbamazepine, phenytoin, St. John's wort, as well as drugs with P-glycoprotein inhibitors, such as posaconazole, tacrolimus, protease inhibitors, including ritonavir, which reduce the bioavailability and thus the plasma levels of dabigatran, is not recommended (53).

\section{Rivaroxaban}

Rivaroxaban is subject to the metabolism of the CYP3A4 system and is a substrate of P-glycoprotein transporters. When administered concomitantly with inhibitors of these enzyme systems, the plasma levels 


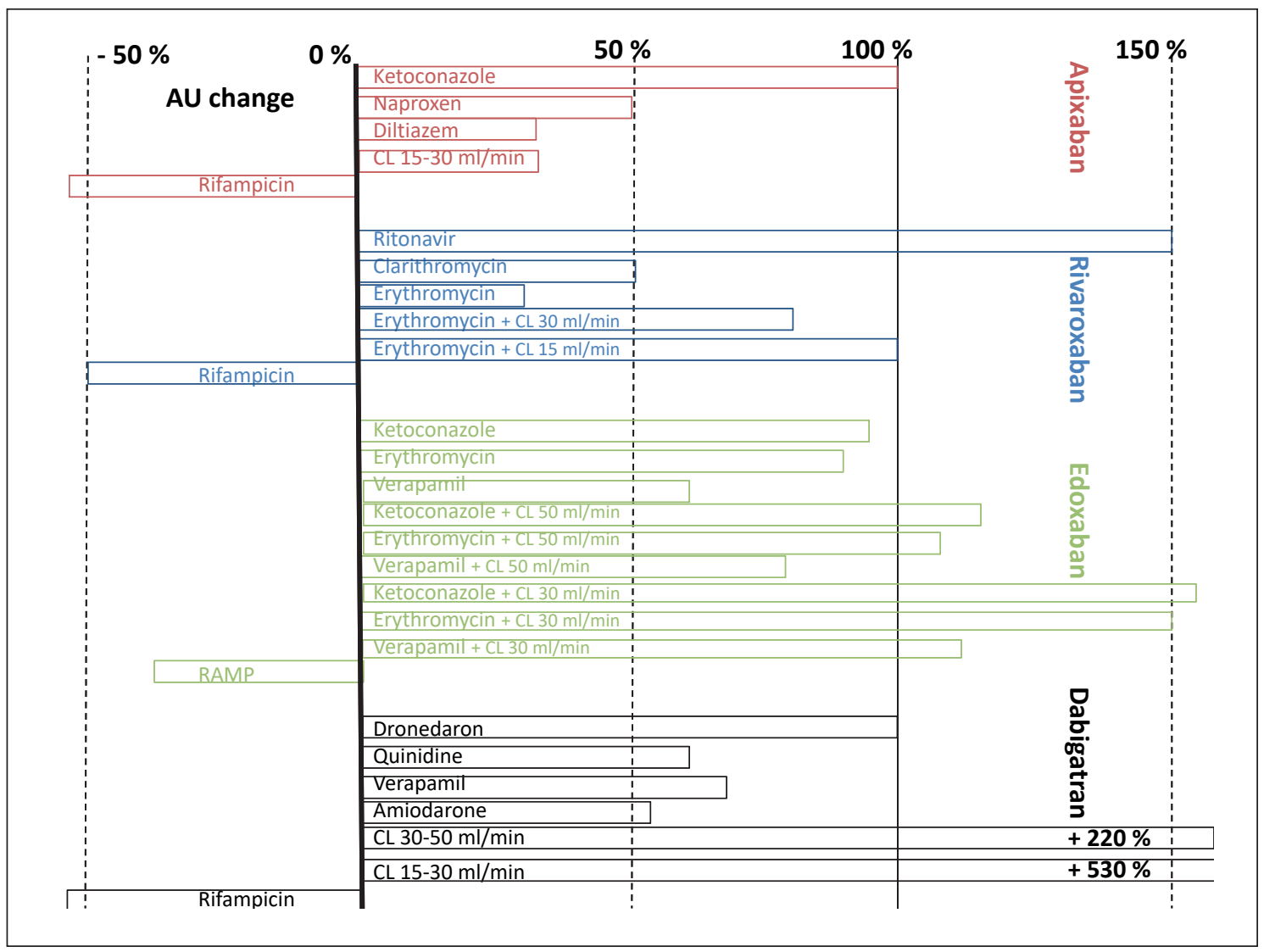

Fig. 1

Exposure of the drug at steady state as the percentage change in concentration (AU) when compared to the first dose (according to 50-56) (RAMP: Receptor activity-modifying protein (cellular transport); CL: Creatininclearence in $\mathrm{ml} / \mathrm{min}$ ). rise. Use of rivaroxaban is therefore not recommended in patients receiving concomitant systemic treatment with azole antifungals (such as ketoconazole, itraconazole, voriconazole and posaconazole) or HIV protease inhibitors (e.g., ritonavir), as this may lead to an increased risk of bleeding $(20,51,52)$. Concomitant administration of rivaroxaban with strong CYP3A4 inducers (e.g., rifampicin, phenytoin, carbamazepine, phenobarbital or "St. John's wort" (Hypericum perforatum) may reduce plasma concentrations of rivaroxaban and therefore should be avoided (51). However, if non-recommended co-medications are necessary, the patient should be closely monitored for signs and symptoms of adverse effects such as thrombosis. Concomitant administration of rivaroxaban and $500 \mathrm{mg}$ naproxen has not been shown to lead to clinically relevant prolongation of bleeding time. Although no clinically significant pharmacokinetic or pharmacodynamic interactions were observed with concomitant administration of rivaroxaban and ASA (500 mg) or clopidogrel (300 mg initial dose followed by $75 \mathrm{mg}$ maintenance dose), the EMA recommends careful use of rivaroxaban and NSAIDs (including ASA) plus antiplatelet agents due to the increased risk of bleeding $(20,51,52)$.

\section{Apixaban}

The use of apixaban is not recommended in patients receiving concomitant systemic treatment with strong CYP3A4 and P-glycoprotein inhibitors, such as azole antifungals (e.g., ketoconazole, itraconazole, voriconazole and posaconazole) and HIV protease inhibitors (e.g., ritonavir) $(21,56)$. These drugs may increase plasma levels of apixaban by a factor of 2 or more in the presence of additional factors that reduce apixaban elimination (e.g., severe renal impairment with GFR 15-30 $\mathrm{ml} / \mathrm{min}$ ).

In contrast, concomitant use of apixaban with strong inducers of CYP3A4 and P-glycoprotein (for example: rifampicin, phenytoin, carbamazepine, phenobarbital or St. John's wort) may lead to a reduction in apixaban plasma levels of up to approxi- mately 50\%. In patients who are concomitantly treated with those drugs, apixaban is not recommended for use in the treatment of venous thromboembolisms (56). Concomitant use with other anticoagulants is contraindicated due to the increased risk of bleeding risk. This risk is significantly increased particularly in patients under socalled „triple“ anticoagulation regimens that include ASA and ADP-receptor blockers after percutaneous coronary intervention (PCI) with stent placement $(21,56)$.

\section{Edoxaban}

Edoxaban is absorbed primarily in the upper gastrointestinal tract $(22,50,55)$. Thus, drugs that accelerate gastric emptying and increase intestinal motility may reduce release and absorption of edoxaban. Edoxaban is a substrate of the efflux transporter P-glycoprotein. In pharmacokinetic studies, concomitant administration of edoxaban and P-glycoprotein-inhibitors cyclosporine, dronedarone, erythromycin, ketoconazole, quinidine or verapamil re- 
sulted in elevated plasma concentrations of edoxaban. With such a combination, the daily dose of edoxaban should be reduced to $30 \mathrm{mg}(50)$. According to clinical data on concomitant use of edoxaban and quinidine, verapamil or amiodarone, no dose reduction is recommended. The use of edoxaban with other P-glycoprotein-inhibitors, including HIV protease inhibitors, has not been studied. In the ENGAGE AF-TIMI 48 study, concomitant use of thienopyridines (e.g., clopidogrel) as monotherapy was allowed and was associated with a higher rate of clinically relevant bleeding $(9,22)$. However, the risk of bleeding with edoxaban was lower than with warfarin. There is very limited experience with the combined use of edoxaban with a dual platelet aggregation inhibitor or with fibrinolytics. According to the authors' opinion, this should only be attempted with caution and close clinical monitoring. In clinical trials, the concomitant use of NSAIDs increasingly led to clinically relevant bleeding $(9$, 22, 50). The long-term use of NSAIDs together with edoxaban is not recommended. The concomitant use of edoxaban and other anticoagulants is contraindicated due to the increased risk of bleeding. However, the concomitant use of low-dose ASA ( $\leq$ $100 \mathrm{mg}$ ) had no impact on the edoxaban peak levels or total exposure (55), indicating that edoxaban may safely be used together with low-dose ASA ( $\leq 100 \mathrm{mg} /$ day).

\section{Persistence of DOACs}

Non-adherence to medications is a worldwide phenomenon that has dangerous and expensive consequences. According to a WHO report, in developed countries, only $50 \%$ of patients on average with chronic diseases are adherent (31). The costs to the US health care system of drug nonadherence are estimated to be approximately 300 billion dollars per year. This represents approximately $13 \%$ of the total cost of the US health care system (32). The main cost drivers are avoidable hospitalizations that cost approximately 100 billion dollars. In Germany, these costs are estimated at 7.5 10 billion euro per year (33). Despite the results from DOAC registration studies (e.g., DOACs adherence in the treatment of acute venous thromboembolism reported to be between $94-99 \%$ ), the first registry and meta-analyses provide sobering results regarding the level of adherence. Approaches to improving the adherence of DOACs in cases of long-term usage are urgently needed. Current data suggest that persistence is the primary guiding force that improves adherence.

In a large meta-analysis (18 randomized controlled trials) that included 101,801 patients (34), the rate of discontinuous intake of DOACs did not differ significantly from that of the comparable therapies for venous thrombosis (risk ratio [RR], 0.91; 95\% CI, $0.74-1.13 ; \mathrm{P}=0.40)$ as well as the comparable therapies (warfarin, ASA) for prophylaxis of ischaemic cerebral infarct in patients with non-valvular atrial fibrillation (RR, 1.01; 95\% CI, 0.87-1.17; P = 0.92).

The studies found no detectable improvement in persistence with oral anticoagulation with DOACs compared with vitamin $\mathrm{K}$ antagonists. For example, only $50 \%$ of patients prescribed DOACs for atrial fibrillation took the oral anticoagulants as prescribed (35). Persistence has traditionally been a major challenge for patients taking oral anticoagulants $(37,38)$. The question is whether the situation is any better with the new oral anticoagulants (DOACs) under real-life conditions. In a registry analysis, the Dresden research team analysed data on persistence from 1,775 patients with atrial fibrillation treated with rivaroxaban for stroke prevention $(\mathrm{n}=$ $1,200)$ and patients with venous thromboembolism $(n=575)(36)$. According to this study, which was carried out with a high degree of medical oversight, only 13.6 discontinuations per 100 patients per year occurred - a value well below of $23.7 \%$ value in the pivotal study (2). This difference was even more distinct with everyday use of vitamin $\mathrm{K}$ antagonists (VKA). Approximately $30 \%$ of the patients discontinued the treatment in the first year and another $10 \%$ in the second year of treatment $(37,38)$. For 4,863 US veterans with atrial fibrillation, the adherence rate to anticoagulant therapy with dabigatran was only $72.2 \%$ (39). However, this result has to be interpreted in light of substantial variability between the 67 medical institutions included in this study. Factors such as a good selection of the patients, the availability of training, and in particular, structured aftercare were associated with improved persistence. In facilities without such factors, adherence was below $50 \%$, which represents a sustained safety risk for the patients.

This view is supported by results from a Danish registry of 2,960 patients in which similar factors were found to influence better adherence to anticoagulant therapy with dabigatran (40): more than $75 \%$ of the patients showed a persistence of over $80 \%$ in the first year. Patients with a higher morbidity and more frequent physician contact had the highest persistence rate. A recent US health care research study has examined a database of a large US insurance carrier more closely (41) involving nearly 65,000 records. All the patients had atrial fibrillation and started oral anticoagulation for the first time between 2010 and 2014 . Nine out of ten patients had a CHA2DS2-VASc score of more than one. The percentage of patients using vitamin $\mathrm{K}$ antagonists was 59\%, rivaroxaban 19\%, dabigatran $16 \%$ and apixaban $6 \%$. The median follow-up period was 1.1 years. Within this period, $47.5 \%$ of patients treated with DOACs demonstrated good persistence, defined as taking the treatment according to the package insert for at least eight out of ten days. This result was, indeed, significantly better than the result for treatment with vitamin $\mathrm{K}$ antagonists $(40.2 \%, \mathrm{p}<$ 0.001 ), but confirmed a disappointingly low adherence for DOACs. Moreover, the investigation yielded results on the medical consequences of suboptimal persistence with oral anticoagulation. Particularly problematic was poor persistence, as expected, in patients at high risk, specifically a CHA2DS2-VASc score of four or above. Patients in this group with low persistence for more than one month during the follow-up period had an incidence of stroke at least twice as high as those who only showed non-adherence for less than seven days. The risk of stroke increased with the degree of nonpersistence. The risk of stroke in patients with lower $\mathrm{CHA}_{2} \mathrm{DS}_{2}$-VASc score (2 or 3 ) was significantly increased only when they did not take their medi- 
cation as prescribed for more than six months in total.

Taking together, the data confirm that persistence in anticoagulated patients with atrial fibrillation, deep vein thrombosis / pulmonary embolism is more important for the prognosis than the type of anticoagulation. This suggests that new approaches are urgently needed to improve drug adherence, e.g., via mobile communications through social networks, e-mails, electronic messaging, offers for training, and in particular, structured aftercare, whose effect must be examined in the future in structured care studies.

In this context, the quality of the available care studies remains problematic. In a meta-analysis of 182 studies that examined various approaches to improve persistence, only 17 studies (9.3\%) fulfilled quality standards for analysis (42). In only 5 of these studies was an improvement in patients' health (outcome criterion) detectable. The situation with current studies is sobering, and so far, no general recommendations for improving persistence can be provided.

\section{Conflicts of Interest}

Adj. Prof. Dr. J. Koscielny declares the following conflicts of interest: speaker honoraria from Aspen, Bayer Health Care Pharmaceuticals, Daiichi Sankyo, Boehringer Ingelheim, CSL Behring, Sanofi-Aventis, Pfizer, BMS, Mitsubishi Pharma, Ferring $\mathrm{GmbH}$, Mylan Healthcare $\mathrm{GmbH}$ and Novo Nordisk. Adj. Prof. Dr. J. Koscielny is also a medical advisor for CSL Behring International, Bayer HealthCare Pharmaceuticals (national and international) and Novo Nordisk (national) for the last three years.

Dr. C. Rosenthal received honoraria and/ or travel reimbursements over the last three years for lectures and consultancy work related to the topic of this article from Bayer AG, Boehringer Ingelheim, CSL Behring, Daiichi Sankyo, NovoNordisk, Pfizer $\mathrm{GmbH}$ and TEM International.

Prof. Dr. C. von Heymann received honoraria and/or travel reimbursements over the last three years for lectures and consultancy work related to the topic of this article from Bayer AG, Shire, Boehringer Ingelheim, Pfizer GmbH, Bristol Myers Squibb,
Daiichi Sankyo, CSL Behring, Leo Pharma, Mitsubishi Pharma, NovoNordisk, Ferring GmbH, Mylan Healthcare GmbH, SanofiAventis and HICC GbR.

\section{References}

1. Healey JS, Eikelboom J, Douketis J et al. Periprocedural bleeding and thromboembolic events with dabigatran compared with warfarin: Results from the Randomized Evaluation of Long-Term Anticoagulation Therapy (RE-LY) Randomized Trial. Circulation 2012; 126: 343-348.

2. Patel MR, Mahaffey KW, Garg J et al. Prevention of stroke and systemic embolism using the oral direct Factor Xa inhibitor rivaroxaban compared with warfarin in patients with nonvalvular atrial fibrillation: the ROCKET AF trial. N Engl J Med 2011; 365: 883-891.

3. Granger CB, Alexander JH, McMurray JJ et al. Apixaban versus warfarin in patients with atrial fibrillation. N Engl J Med 2011; 365 (11): 981-992.

4. The EINSTEIN Investigators. Oral rivaroxaban for symptomatic venous thromboembolism. N Engl J Med 2010; 363: 2499-2510.

5. The EINSTEIN-PE Investigators. Oral Rivaroxaban for the Treatment of Symptomatic Pulmonary Embolism. N Engl J Med 2012; 366: 1287 1297.

6. Turpie AGG, Lassen MR, Eriksson BI et al. Rivaroxaban for the prevention of venous thromboembolism after hip or knee arthroplasty. Pooled analysis of four studies. Thromb Haemost 2011; 105: 444-453.

7. The EINSTEIN Investigators. Oral rivaroxaban for symptomatic venous thromboembolism. N Engl J Med 2010; 363: 2499-2510.

8. Mega JL, Braunwald E, Mohanavelu S, et al. Rivaroxaban versus placebo in patients with acute coronary syndromes (ATLAS ACS-TIMI 46): a randomised, double-blind, phase II trial. Lancet 2009; 374: 29-38.

9. Giugliano RP. Edoxaban versus Warfarin in Patients with Atrial Fibrillation et al. N Engl J Med 2013; 363: 2093-104.

10. The Hokusai-VTE Investigators. Edoxaban versus Warfarin for the Treatment of Symptomatic Venous Thromboembolism. N Engl J Med 2013; 369: 1406-1415.

11. Heidbuchel H, Verhamme P, Alings M et al. Updated European Heart Rhythm Association (EHRA) Practical Guide on the use of non-vitamin $\mathrm{K}$ antagonist anticoagulants in patients with non-valvular atrial fibrillation. Europace 2015; 17(10): 1467-1507.

12. Pernod G, Albaladejo P, Godier A et al.; Working Group on Perioperative Haemostasis. Management of major bleeding complications and emergency surgery in patients on long-term treatment with direct oral anticoagulants, thrombin or factor-Xa inhibitors: proposals of the working group on perioperative haemostasis (GIHP) - March 2013. Arch Cardiovasc Dis 2013; 106(6-7): 382-393.

13. Eisele $\mathrm{R}$ et al. Perioperatives Gerinnungsmanagement bei oraler Antikoagulation. Chirurg 2014; 85: 513-519.
14. Giebl A, Gürtler K. Neue orale Antikoagulanzien in der perioperativen Medizin. Anaesthesist 2014; 63: 347-364.

15. Arbeitsgemeinschaft der Wissenschaftlichen Medizinischen Fachgesellschaften (AMWF). S3-Leitlinie Prophylaxe der venösen Thromboembolie (VTE). AWMF-Registernr 003/001 Klasse S3; 2015.

16. von Heymann C, Koscielny J. Update: Patienten unter oraler Antikoagulation mit VKA oder NOAK - Perioperatives „Bridging“ oder „„,Switching“?"Anästh Intensivmed 2016; 57: 316-331.

17. Waurick K, Riess H, Van Aken H et al. S1-Richtlinie: Rückenmarksnahe Regionalanästhesien und Thromboembolieprophylaxe/ antithrombotische Medikation. 3. überarbeitete Empfehlung der Deutschen Gesellschaft für Anästhesiologie und Intensivmedizin, Anästh Intensivmed 2014; 55 : 464-492.

18. Sporbeck B, Bechara FG, Häfner HM et al. S3-Leitlinie zum Umgang mit Antikoagulation bei Operationen an der Haut. JDDG: Journal der Deutschen Dermatologischen Gesellschaft 2015; 13: 346-357.

19. EMA - Dabigatran. www.ema.europa.eu/docs/ de_DE/document_library/EPAR_Product_Information/human/000829/WC500041059.pdf

20. EMA - Rivaroxaban. http://www.ema.europa.eu/ docs/de_DE/document_library/EPAR_-_Product_Information/human/ 000944/WC500057108.pdf

21. Pfizer - Apixaban. http://www.pfizer.de/filead min/produktdatenbank/pdf/Eliquis_5mg_FI_01.pdf

22. EMA - Edoxaban. http://ec.europa.eu/health/ documents/communityregister/2015/20150619132091/anx_132091_de.pdf

23. Beyer-Westendorf J, Förster K, Pannach S et al. Rates, management, and outcome of rivaroxaban bleeding in daily care: results from the Dresden DOAC registry. Blood 2014; 124(6): 955-962.

24. Beyer-Westendorf J, Gelbricht V, Förster K et al. Peri-interventional management of novel oral anticoagulants in daily care: results from the prospective Dresden NOAC registry. Eur Heart J 2014; 35(28): 1888-1896.

25. Steinberg BA, Peterson ED, Kim S, Thomas L, Gersh BJ, Fonarow GC, Kowey PR, Mahaffey KW, Sherwood MW, Chang P, Piccini JP, Ansell J; Outcomes Registry for Better Informed Treatment of Atrial Fibrillation Investigators and Patients. Use and outcomes associated with bridging during anticoagulation interruptions in patients with atrial fibrillation: findings from the Outcome Registry for Better Informed Treatment of Atrial Fibrillation (ORBIT-AF). Circulation 2015; 131(5): 488-494.

26. Camm AJ, Amarenco P, Haas S, Hess S, Kirchhof P. Kuhls S, van Eickels M, Turpie AGG, the XANTUS Investigators. XANTUS: a real-world, prospective, observational study of patients treated with rivaroxaban for stroke prevention in atrial fibrillation. Eur Heart J 2016; 37(14): 1145-1153

27. Schulman S et al. Perioperative Management of Dabigatran: A Prospective Cohort Study. Periop Dabigatran Study Group. Circulation 2015; 132(3): 167-173.

28. Douketis JD et al. Effect of standardized perioperative dabigatran interruption on the residual anti- 
coagulation effect at the time of surgery or procedure. J Thromb Haemost 2016; 14(1): 89-97.

29. Mallet $\mathrm{L}$ et al. The challenge of managing drug interactions in elderly people. Lancet 2007; 370(9582): 185-191.

30. Far $\mathrm{E}$ et al. Validation of a transparent decision model to rate drug interactions. BMC Pharmacol Toxicol 2012; 13: 7 .

31. WHO: Adherence to long-term therapies. Evidence for action. ISBN 924154599 2. 2003; 1-209.

32. NEHI (New England Healthcare Institute). (2009). Thinking Outside the Pillbox: A System-wide Approach to Improving Patient Medication Adherence for Chorionic Disease. http://www.nehi.net/ publications/44/thinking_outside_the_pillbox_a_systemwide_approach_to_improving_patient_medication_adherence_for__chronic_disease. Last accessed October 2011.

33. Gräf M. Die volkswirtschaftlichen Kosten der Non-Compliance: Eine entscheidungsorientierte Analyse. Gesundheitsökonomie Band 56. Bayreuth, P.C.O.-Verlag, 2007.

34. Chatterjee $S$ et al. Treatment Discontinuations With New Oral Agents for Long-term Anticoagulation: Insights From a Meta-analysis of 18 Randomized Trials Including 101,801 Patients. Mayo Clinic Proceedings 2014; 89(7): 896-907.

35. Rodriguez RA, Carrier M, Wells PS. Non-adherence to new oral anticoagulants: a reason for concern during long-term anticoagulation? J Thromb Haemost 2013; 11(2): 390-394.

36. Beyer-Westendorf J et al. Drug persistence with rivaroxaban therapy in atrial fibrillation patients-results from the Dresden non-interventional oral anticoagulation registry. Europace 2015; 17(4): 530-538.

37. Gomes $\mathrm{T}$ et al. Persistence with therapy among patients treated with warfarin for atrial fibrillation. Arch Intern Med 2012; 172(21): 1687-1689.

38. Gallagher AM et al. Initiation and persistence of warfarin or ASA in patients with chronic atrial fibrillation in general practice: do the appropriate patients receive stroke prophylaxis? J Thromb Haemost 2008; 6(9): 1500-1506.
39. Shore S, Ho MP, Lambert-Kerzner A, et al. Sitelevel variation in and practices associated with dabigatran adherence. JAMA 2015; 313: 1443-1450.

40. Gorst-Rasmussen A, Skjøth F, Larsen TB, et al. Dabigatran adherence in atrial fibrillation patients during the first year after diagnosis: a nationwide cohort study. J Thromb Haemost 2015; 13 : 495-504

41. Yao X et al. Effect of Adherence to Oral Anticoagulants on Risk of Stroke and Major Bleeding Among Patients With Atrial Fibrillation. J Am Heart Assoc 2016; 5(2): 1-12.

42. Nieuwlaat R, Wilczynski $\mathrm{N}$ et al. Interventions for enhancing medication adherence. Interventions for enhancing medication adherence. Cochrane Database Syst Rev 2014; 11: 1-732.

43. Garcia D, Alexander JH, Wallentin L, Wojdyla DM, Thomas L, Hanna M et al. Management and clinical outcomes in patients treated with apixaban vs warfarin undergoing procedures. Blood 2014 124: 3692-3698.

44. Breuer G, Weiss DR, Ringwald J. ,New' direct oral anticoagulants in the perioperative setting. Curr Opin Anaesthesiol 2014; 27: 409-419.

45. Koscielny J, Beyer-Westendorf J, von Heymann C, Braun J, Klamroth R, Lindhoff-Last E et al. [Risk of bleeding and haemorrhagic complication with rivaroxaban--periprocedural management of haemostasis]. Hamostaseologie 2012; 32: 287-293.

46. Spannagl M, Bauersachs R, Debus ES, Gawaz M, Gerlach H, Haas S et al. [Dabigatran therapy perioperative management and interpretation of coagulation tests]. Hamostaseologie 2012; 32: 294-305.

47. Douketis JD, Healey JS, Brueckmann M, Eikelboom JW, Ezekowitz MD, Fraessdorf M et al. Perioperative bridging anticoagulation during dabigatran or warfarin interruption among patients who had an elective surgery or procedure. Substudy of the RE-LY trial. Thrombosis and haemostasis 2015; 113: 625-632.

48. Beyer-Westendorf J, Ebertz F, Forster K, Gelbricht V, Michalski F, Kohler C et al. Effectiveness and safety of dabigatran therapy in daily-care patients with atrial fibrillation. Results from the Dresden NOAC Registry. Thrombosis and haemostasis 2015; 113: 1247-1257.

49. Kessler P, Steinfeldt T, Gogarten W, Schwemmer U, Buttner J, Graf BM et al. [Peripheral regional anesthesia in patients under general anesthesia: risk assessment with respect to parasthesia, injection pain and nerve damage]. Anaesthesist 2013; 62: $483-488$.

50. Salazar DE. et al. Modelling and simulation of edoxaban exposure and response relationships in patients with atrial fibrillation. Thromb Haemost 2012; 107(5): 925-936.

51. Mueck W. et al. Co-administration of rivaroxaban with drugs that share its elimination pathways: pharmacokinetic effects in healthy subjects. Br J Clin Pharmacol 2013; 76: 455-466.

52. Moore KT et al. An open-label study to estimate the effect of steady-state erythromycin on the pharmacokinetics, pharmacodynamics, and safety of a single dose of rivaroxaban in subjects with renal impairment and normal renal function. J Clin Pharmacol 2014; 54(12): 1407-1420.

53. Lehr T. et al. Dabigatran etexilate in atrial fibrillation patients with severe renal impairment: dose identification using pharmacokinetic modeling and simulation. J Clin Pharmacol 2012; 52(9): 1373-1378.

54. Stangier J et al. Influence of renal impairment on the pharmacokinetics and pharmacodynamics of oral dabigatran etexilate: an open-label, parallelgroup, single-centre study. Clin Pharmacokinet 2010; 49(4): 259-268.

55. Mendell J. et al. The Effect of Rifampin on the Pharmacokinetics of Edoxaban in Healthy Adults. Clinical Drug Investigation 2015; 35(7): 447-453.

56. Chang M. et al. Effect of renal impairment on the pharmacokinetics, pharmacodynamics, and safety of apixaban. J Clin Pharmacol 2016; 56(5): 637-645. 